\title{
MAESTRO VICO
}

\section{María José Rebollo Espinosa}

(Universidad de Sevilla)

RESUMEN: En esta contribución al número especial de la revista, repaso y describo mi peculiar forma de ver a Vico: miro con ojos de educadora a quien fuera un filósofo preocupado crítica y constructivamente por la educación de su tiempo.

Palabras CLAVE: Vico, $350^{\circ}$ Aniversario, pedagogía viquiana, educación, M.J. Rebollo Espinosa.

\section{Master Vico}

ABSTRACT: In this contribution to the special issue of the magazine I review and describe my peculiar understanding of Vico: I look with the eyes of an educator at a philosopher that was worried critically and constructively for the education of his time.

KeYworDS: Vico, $350^{\text {th }}$ Anniversary, Vichian pedagogy, education, M.J. Rebollo Espinosa.

\section{Maestro Vico}

RIASSUNTO: In questo contributo al numero speciale della rivista, ripercorro e descrivo il mio peculiare modo di intendere Vico, ovvero guardo con gli occhi di un'educatrice colui che, in fondo, era un filosofo preoccupato in modo critico e costruttivo per l'educazione del suo tempo.

Parole ChiAVE: Vico, $350^{\circ}$ Anniversario, pedagogia vichiana, educazione, M.J. Rebollo Espinosa.

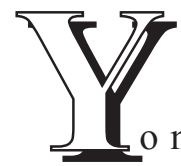

no me considero una experta en Vico. De hecho, hace casi veinte años que no escribo nada sobre él, aunque siga estando bastante al día en este ámbito de investigación porque mis funciones en el Consejo de Redacción de Cuadernos sobre Vico, como correctora y traductora desde 1997, implican llevar a cabo de forma periódica una selección de lecturas viquianas de lo más granado.

Es más, ni siquiera soy filósofa de formación, sino pedagoga. Desde hace mucho imparto docencia principalmente en Historia de la Educación, en cuyos manuales, por cierto, Vico rara vez aparece reflejado como figura importante.

Este artículo responde a una invitación expresa por parte de la Dirección de la Revista para este volumen especial por el $350^{\circ}$ Aniversario del nacimiento de G. Vico, habiendo superado los criterios de valoración y del proceso de aceptación. 
Entonces, ¿qué hace una chica -no tan chica- como yo en un sitio como este? ¿Por qué participar en este número especial de la Revista? Me respondo a mí misma diciendo que lo hago, sin llegar a eliminar del todo mi sensación de extrañamiento, en primer lugar, por un compromiso de amistad con el director, cuya insistencia y perseverancia en la consecución de sus objetivos es más que notable. Por otro lado, lo hago también para no perder la oportunidad única de estar testimonialmente presente en esta publicación que conmemora el trescientos cincuenta aniversario del nacimiento de un autor al que he trabajado durante una etapa de mi trayectoria académica. Y, además, me he decidido a hacerlo también a modo de ejercicio de autorreflexión, de repaso a mi recorrido en esta área de estudio, tarea que, de vez en cuando, creo que debe hacer una historiadora: volver la vista atrás y narrar, hacer un relato historiográfico de sus propios acontecimientos vitales, puesto que en la historia sujeto y objeto están indefectiblemente imbricados.

La mía ha sido siempre, pues, una perspectiva mediada por el punto de vista educativo, incardinada en el estudio de la historia del pensamiento pedagógico europeo, de ahí que mi breve contribución -alabo la virtud de la síntesis- gire en torno al Vico maestro en un sentido amplio del término, en homenaje al que fuera en su época un profesor de Retórica, quizá no suficientemente reconocido por la institución universitaria, y un teórico de la educación poco escuchado. En este sentido me propongo apuntar cuáles han sido mis aportaciones a los estudios viquianos en dicha línea y rastrear asimismo qué he aprendido yo de Vico, qué ha quedado de viquiano en mí, consciente de que me resultará muy difícil responder a estas cuestiones, aparentemente simples, sin desnudarme personal e intelectualmente, sin mentir para ser políticamente correcta (un defecto de nuestro actual sistema universitario o, según se mire, una de las "competencias" que no he querido ni podido dominar, para mi desgracia).

En un principio, Vico representó para mí una salida, la respuesta académica a un atolladero intelectual. Tras muchas dudas y cambios de tema, a sugerencia de José Manuel Sevilla Fernández y bajo su dirección (compartida con la de María Nieves Gómez García, catedrática de Historia de la Educación), hice mi Tesis Doctoral sobre las Claves pedagógicas del pensamiento viquiano, que luego se publicó bajo el título de Dioses, héroes y hombres. G. Vico, teórico de la educación. En aquel momento fue una investigación oportuna, porque no había mucho sobre ello en el panorama europeo y americano, y menos aún en el español. Además, el viaje a Italia como parte del proceso de recogida de información para ese estudio (siguiendo la eficaz guía bibliográfica de Manuela Sanna) marcó uno de los momentos más felices de mi vida, y las recompensas personales son fundamentales a mi entender. 
De la Tesis derivaron igualmente otros trabajos, que fueron presentados a Congresos, ${ }^{1}$ como artículos en esta y otras revistas, ${ }^{2}$ o que incluso sirvieron de base a algún curso de doctorado. ${ }^{3}$ El objetivo de este conjunto de trabajos, el hilo argumental que los unió fue doble: sistematizar, por un lado, las ideas sobre educación que Vico vertió diseminadas por toda su obra -traicionando hasta cierto punto su inconfundible estilo barroquizante-; y, por otro lado, aprovecharlas, actualizándolas, para comprender y mejorar la educación de hoy, que seguramente se enfrenta a problemas similares a los de entonces (abuso de un racionalismo mal entendido, exceso de especialización, falta de espíritu crítico, etc.) y puede en ellas hallar pistas para enmendarlos. Para desarrollar estas investigaciones, sin obviar los más reconocidos, profundicé en especial en textos viquianos menores, sobre todo en las Oraciones Inaugurales, en la Autobiografia, en el De Antiquissima y en el epistolario, menos atendidos habitualmente, pero de donde era mucho más natural y fructífero extraer sus opiniones, experiencias y propuestas educativas.

En esas fuentes encontré el material preciso para desentrañar los argumentos del historicismo pedagógico viquiano, un olvidado ejemplo de innovación educativa: la concepción de los procesos educativos como integrales, perfeccionadores, activos, graduales, globalizados, sociales e individuales a la vez; la imagen de un educador "moderno", que active la bidireccionalidad de la comunicación educativa, que practique la no-directividad, que parta del paidocentrismo y del humanismo; la apuesta por la imprescindible organicidad de las materias curriculares a fin de lograr aprendizajes más significativos; o las orientaciones para aprender a conocer, hacer, convivir y ser, los cuatro pilares que mucho más tarde reivindicaría a la UNESCO un famoso informe de cara a la educación del siglo XXI.

Pero mi propia personalidad -que me impide perseverar demasiado tiempo en los mismos quehaceres sin agotarme por aburrimiento-y las circunstancias universitarias que me fueron rodeando - coincidiendo casualmente con el cambio de siglo-, hicieron que Vico se fuese quedando atrás en mis intereses investigadores, que fueron derivando hacia ámbitos bien distintos, orientándose hacia el campo de los Estudios de Género y de la Historia de la Educación de las Mujeres en particular, para acabar aterrizando más recientemente en lo relacionado con la museología

1. Cfr. M.J. RebolLo, «El árbol del conocimiento viquiano: bases para una propuesta actual del curriculum universitario», en AA.VV., La universidad en el siglo XX: España e Iberoamérica, Universidad de Murcia, 1998, pp. 424432; «Vico-Delors-Vico: la educación encierra un tesoro», en AA.VV., Pensar para el nuevo siglo. Giambattista Vico y la cultura europea, E. Hidalgo-Serna, M. Marassi, J.M SeVilla, J. Villalobos (editores), La Città del Sole, Nápoles, 2000, vol. II, pp. 873-898; «Ricorsi a la pedagogía viquiana», en AA.VV., Il mondo di Vico, Vico nel mondo, F. RATTO (COORD.), Edizioni Guerra, Perugia, 2000, pp. 369-382.

2. Cfr. M.J. ReBollo, «El educador viquiano», Cuadernos sobre Vico, 7-8, 1997, pp. 181-190; ID., «G. Vico: prehistoria de la Educación Nueva», Cuadernos de Pedagogía, 13, 1997, pp. 39-51; ID., «Vico: la permanente educabilidad», Cuadernos sobre Vico, 9-10, 1998, pp. 163-174; ID., «Isaiah Berlin: claves axiológicas para una educación humanística», Educaçao e Filosofia, vol. 15, n 30, 2001, pp. 67-88.

3. Curso de Doctorado titulado «Humanismo pedagógico: Vico y Berlin». 
y el patrimonio histórico educativo (en la actualidad dirijo el Museo Pedagógico de la Facultad de Ciencias de la Educación de la Universidad de Sevilla). ${ }^{4}$

Después de abandonarlo como núcleo casi exclusivo de estudio -confieso que la mía con Vico siempre ha sido una relación de amor-odio-me planteo, impulsada por la obligación teórica asumida de escribir sobre esta cuestión, si el napolitano ha dejado alguna huella en mi pensar y actuar, si ha ejercido como maestro también para mí, como parece ser que ha sucedido con tantas otras personas que han sentido y sienten su magisterio hasta el punto de haber dado lugar a una escuela viquiana. Rastreando secuelas de viquianismo en mí, puedo apuntar, entre otros elementos, los siguientes:

Reconozco mi admiración por sus magníficas intuiciones, aunque no admito la tan difundida tesis del precursorismo, porque, como historiadora, soy incapaz de interpretar a ningún autor separándolo de su contexto vital: nadie puede adelantarse a su época, si acaso darle un empujoncito para avanzar.

Aplaudo y defiendo su criterio del verum ipsum factum, eje de la razón histórica, como principio vital, más allá de entenderlo como referencia científica: nuestros actos son los que determinan de verdad lo que somos, en un mundo atiborrado de teorías vacías y postverdades.

Me parece igualmente genial su teoría de los corsi e ricorsi, su esquema ontogenético de la evolución de la historia de las naciones, puesto que proporciona una explicación clara, fuertemente visual y simbólica de las edades de la humanidad, de la que se deduce una advertencia para los lectores de hoy, que sufrimos multitud de indicios de la barbarie de la reflexión, quizá con un atisbo de esperanza gracias a él.

Comparto también su postura "anticartesiana" frente a la educación, ya que subraya la necesidad de no constreñir el pensamiento con las rigideces de la metodología analítica. A esta opone la tópica, la lógica del descubrimiento, del saber práctico, de la argumentación, del pensar problemático que implica cultivar otras facultades humanas aparte de la razón, fomentar la memoria, el ingenio, la fantasía, etc. Recomendación que ha calado en el marco didáctico que fundamenta mi enfoque de la asignatura que imparto como docente, en la que animo al alumnado a desarrollar la imaginación histórica y a estudiar el pasado de la educación poniendo en juego habilidades y recursos creativos y sensoriales que a menudo se anquilosan porque la inercia académica no considera serio, quizá, ponerlos en práctica.

Utilizo también a menudo en mis clases la etimología de las palabras como clave interpretativa y comprensiva de los conceptos que necesito definir al alumna-

4. Consigno en esta nota a pie de página mi deseo, nunca cumplido, de escribir alguna vez para esta revista un artículo que casara indirectamente mi "pasado" viquiano con este foco de interés académico más reciente, puesto que el proyecto era profundizar en la poco conocida figura de la hija del napolitano y para el cual solo he pensado el título: "Anfitrionas de cultura: a propósito de Luisa Vico". 
do y, cuando lo hago, no puedo dejar de acordarme tampoco de Vico, es una riqueza que me gustaría transmitir a los estudiantes.

Pero, sin duda, el precepto viquiano que más efecto ha causado en mí es el que sirve de exordio a nuestra publicación, esa cita del proemio del De Antiquissima que reza: «nosotros, que no pertenecemos a ninguna secta, hemos de indagar». Cada vez más, y a pesar de los inconvenientes que lleva consigo, procuro actuar con la libertad que las circunstancias me permiten, a sabiendas de la comodidad que supone el sentirse miembro convencido de un grupo que impone sus directrices y de los problemas que puede ocasionar vivir académicamente en los márgenes del sistema.

En definitiva, parece que sí conservo cierto "poso" viquiano. Este filósofo del Sur -puede que las coordenadas geográficas cercanas propicien las convergencias, como él pensaba- continúa estando de alguna manera prendido en mi espíritu (y en el de otras muchas personas de muy distinta formación), sin alharacas, sin llegar a creer del todo en su "genialidad", sin entender siquiera cómo no explota la que a veces me parece una "burbuja viquiana", o cómo en el estado actual de precariedad de la cultura existen y sobreviven centros de estudios y revistas como esta que, paradójicamente, contribuyo a mantener en marcha. Creo que, si el maestro Vico levantara la cabeza, se sorprendería de su éxito -o no, puesto que tenía bastante fama de engreído y no esperaría otra cosa-, estaría ciertamente orgulloso de su legado, de que, pasados 350 años de su nacimiento, sigamos hablando de él y de sus maravillosas y "locas" intuiciones, en varias lenguas y desde puntos distantes del mundo, quizá confiando en que nos eche un cable para recuperar cordura.

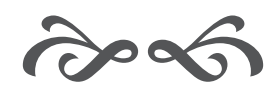


<smiles>[As]</smiles> 